\title{
Microbeam Characterization of Corning Archeological Reference Glasses: New Additions to the Smithsonian Microbeam Standard Collection
}

\section{Edward P. Vicenzi}

Smithsonian Institution, National Museum of Natural History, Department of Mineral Sciences, Washington, DC 20560-0119

\section{Stephen Eggins}

Research School of Earth Sciences, Australian National University, 0200, Canberra

ACT, Australia

and

\section{Amelia Logan and Richard Wysoczanski}

Smithsonian Institution, National Museum of Natural History, Department of Mineral Sciences, Washington, DC 20560-0119

\author{
An initial study of the minor element, trace \\ element, and impurities in Corning \\ archeological references glasses have \\ been performed using three microbeam \\ techniques: electron probe microanalysis \\ (EPMA), laser ablation ICP-mass \\ spectrometry (LA ICP-MS), and secondary \\ ion mass spectrometry (SIMS). The \\ EPMA results suggest a significant level of \\ heterogeneity for a number of metals. \\ Conversely, higher precision and a larger \\ sampling volume analysis by LA ICP-MS \\ indicates a high degree of chemical \\ uniformity within all glasses, typically \\ $<2 \%$ relative $(1 \sigma)$. SIMS data reveal that \\ small but measurable quantities of \\ volatile impurities are present in the \\ glasses, including $\mathrm{H}$ at roughly the \\ 0.0001 mass fraction level. These glasses \\ show promise for use as secondary \\ standards for minor and trace element \\ analyses of insulating materials such as \\ synthetic ceramics, minerals, and silicate \\ glasses.
}

Key words: chemical heterogeneity; electron probe microanalysis; glass; laser ablation ICP-MS; microbeam; microscale characterization; secondary ion mass spectrometry.

Accepted: August 22, 2002

\section{Introduction}

\subsection{Corning Archeological Reference Glasses: Background}

While it is uncertain precisely when glass making technology first emerged, glass objects are known from Egypt that are approximately 4500 years old. In the early 1960s there was a growing interest among glass scientists to determining the extent of chemical variation in artifacts from cultures that differed both in time and geography. The ability to compare chemical analyses from laboratories across the globe required a set of high quality reference glasses [1]. This need was articulated during the VIth International Congress on Glass in 1963, and compositions representing the major archeological glass types were proposed [2]. Four glasses were subsequently synthesized at the Corning Glass Works and interlaboratory comparisons of their chemistry were coordinated by Dr. Robert Brill of the Corning Museum of Glass [2-4]. 


\subsection{Compositions and Synthesis}

The chemistry of the glasses was chosen to mimic four ancient glass varieties and is summarized by Brill [4]. Each glass was doped with between 29 to 31 elements at the major, minor, and trace levels (Table 1). Glasses A and B represent the composition of those objects typical of Egyptian, Mesopotamian, Roman, Byzantine, and Islamic archeological sites and are Na-rich/Ca-bearing silicates. Glass $\mathrm{C}$ is rich in $\mathrm{Pb}$ and $\mathrm{Ba}$ and is similar in composition to glasses found in East Asia. Glass D is a K- and Ca-rich silicate that approximates some younger, so-called medieval glasses, produced from the 17th to 19th centuries.

Precursor materials consisted dominantly of high purity synthetic oxides and carbonates, but also included
$\mathrm{NaCl}, \mathrm{NH}_{4} \mathrm{H}_{2} \mathrm{PO}_{3}$, alumina hydrate, zircon (natural $\mathrm{ZrSiO}_{4}$ ), and "African sand" as a source of $\mathrm{SiO}_{2}$ [4]. Trace elements were mixed in 2 groups (\#1: Ti, Sn, B, $\mathrm{Ba}, \mathrm{Sr}, \mathrm{Li}$, and $\mathrm{Rb} ; \# 2: \mathrm{V}, \mathrm{K}, \mathrm{Ag}, \mathrm{Zr}, \mathrm{Ni}, \mathrm{Zn}$, and $\mathrm{Bi}$ ) and ball-milled for $16 \mathrm{~h}$ prior to incorporation into $15 \mathrm{~kg}$ batches. This method allowed for constant trace element ratios of metals (within each trace element group) among the four compositions. The precursor mixtures were then melted in platinum crucibles and held at $1450{ }^{\circ} \mathrm{C}$ for $3 \mathrm{~h}$ to $4 \mathrm{~h}$. Melts were stirred with Pt rods and quenched in deionized water. The glasses were then lightly crushed and re-melted at $1450{ }^{\circ} \mathrm{C}$ for another $2 \mathrm{~h}$. The rehomogenized melts were also stirred and finally poured out as $1 \mathrm{~cm}$ thick sheets, which were annealed at $450{ }^{\circ} \mathrm{C}$.

Table 1. Major, minor, and trace element compositions of glasses (Brill, 1999) mass fraction $\times 10^{2}$

\begin{tabular}{|c|c|c|c|c|}
\hline Corning & A & B & C & D \\
\hline USNM \# & 117218.004 & 117218.001 & 117218.002 & 117218.003 \\
\hline $\mathrm{SiO}_{2}$ & $66.56^{\mathrm{a}}$ & $61.55^{\mathrm{a}}$ & $34.87^{\mathrm{a}}$ & 55.24 \\
\hline $\mathrm{Al}_{2} \mathrm{O}_{3}$ & 1.00 & 4.36 & 0.87 & 5.30 \\
\hline $\mathrm{Fe}_{2} \mathrm{O}_{3}$ & 1.09 & 0.34 & 0.34 & 0.52 \\
\hline $\mathrm{MgO}$ & 2.66 & 1.03 & 2.76 & 3.94 \\
\hline $\mathrm{CaO}$ & 5.03 & 8.56 & 5.07 & 14.8 \\
\hline $\mathrm{Na}_{2} \mathrm{O}$ & 14.3 & 17.0 & 1.07 & 1.20 \\
\hline $\mathrm{K}_{2} \mathrm{O}$ & 2.87 & 1.00 & 2.84 & 11.3 \\
\hline $\mathrm{MnO}$ & 1.00 & 0.25 & $0.82^{\mathrm{a}}$ & 0.55 \\
\hline $\mathrm{P}_{2} \mathrm{O}_{5}$ & 0.13 & 0.82 & 0.14 & 3.93 \\
\hline $\mathrm{TiO}_{2}$ & 0.79 & 0.089 & 0.79 & 0.38 \\
\hline $\mathrm{Sb}_{2} \mathrm{O}_{5}$ & 1.75 & 0.46 & 0.03 & 0.97 \\
\hline $\mathrm{CuO}$ & 1.17 & 2.66 & 1.13 & 0.38 \\
\hline $\mathrm{PbO}$ & 0.12 & 0.61 & 36.7 & 0.48 \\
\hline $\mathrm{CoO}$ & 0.17 & 0.046 & 0.18 & 0.023 \\
\hline $\mathrm{BaO}$ & 0.56 & 0.12 & 11.4 & 0.51 \\
\hline $\mathrm{SnO}_{2}$ & 0.19 & 0.04 & 0.19 & 0.10 \\
\hline $\mathrm{SrO}$ & 0.10 & 0.019 & 0.29 & 0.057 \\
\hline $\mathrm{ZnO}$ & 0.044 & 0.19 & 0.052 & 0.10 \\
\hline \multicolumn{5}{|c|}{ Nominal compositions ${ }^{\mathrm{b}}$} \\
\hline $\mathrm{B}_{2} \mathrm{O}_{3}$ & 0.20 & 0.02 & 0.20 & 0.10 \\
\hline $\mathrm{Li}_{2} \mathrm{O}$ & 0.01 & 0.001 & 0.01 & 0.005 \\
\hline $\mathrm{Cl}$ & 0.10 & 0.2 & 0.10 & 0.4 \\
\hline $\mathrm{SO}_{3}$ & 0.10 & 0.5 & 0.10 & 0.3 \\
\hline $\mathrm{Rb}_{2} \mathrm{O}$ & 0.01 & 0.001 & 0.01 & 0.005 \\
\hline $\mathrm{V}_{2} \mathrm{O}_{5}$ & 0.006 & 0.03 & 0.006 & 0.015 \\
\hline $\mathrm{Cr}_{2} \mathrm{O}_{3}$ & 0.001 & 0.005 & 0.001 & 0.0025 \\
\hline $\mathrm{NiO}$ & 0.02 & 0.10 & 0.02 & 0.05 \\
\hline $\mathrm{ZrO}_{2}$ & 0.005 & 0.025 & 0.005 & 0.0125 \\
\hline $\mathrm{Ag}_{2} \mathrm{O}$ & 0.002 & 0.01 & 0.002 & 0.005 \\
\hline $\mathrm{Bi}_{2} \mathrm{O}_{3}$ & 0.001 & 0.005 & 0.001 & 0.0025 \\
\hline Total & 99.94 & 99.87 & 99.95 & 100.59 \\
\hline
\end{tabular}

${ }^{\text {a }}$ From Brill (unpublished data).

${ }^{\mathrm{b}}$ Calculated from precursor mass fractions. 
Participants of analytical round-robins involving these glasses have employed a number of classical bulk chemical techniques, including: gravimetry, volumetry, colorimetry, polarography, flame photometry, and redox titration [4]. Atomic absorption, x-ray fluorescence, neutron activation, and emission spectroscopies have also been conducted to determine the composition of many of the element abundances in the reference glasses [3].

\subsection{Microbeam Characterization}

Although significant effort was spent during the fabrication process to ensure homogeneity in the glasses, an examination of glass chemistry on the submillimeter to micrometer length scale has not been performed. We used three microbeam techniques, electron probe microanalysis (EPMA), laser ablation inductively coupled-mass spectrometry (LA ICP-MS), and secondary ion mass spectrometry (SIMS) to determine (to first order) the minor and trace element characteristics of the glasses. Once the degree of spatial heterogeneity of the minor and trace elements has been established, these materials can be considered for duel purposes in laboratories using microchemical techniques: 1. for use as a secondary standards, and 2. for use as a primary standard for the analysis of elements where more desirable forms (e.g., simple oxides, phosphates, or other stoichiometric compounds) are not available. All four Corning glasses were recently accessioned into the Smithsonian Microbeam Standard (SMS) collection [5] and hence are available for distribution to research laboratories for follow-up and additional characterization.

\section{Electron Probe Microanalysis (EPMA)}

$\mathrm{X}$-ray microanalysis was performed with a five-wavelength dispersive spectrometer (WDS) instrument to analyze for $\mathrm{S}, \mathrm{Cl}, \mathrm{Co}, \mathrm{Cu}, \mathrm{Zn}, \mathrm{Sr}, \mathrm{Sn}, \mathrm{Sb}, \mathrm{Ba}$, and $\mathrm{Pb}$ in glass. An accelerating voltage of $15 \mathrm{keV}$ was used to measure K-line ( $\mathrm{S}, \mathrm{Cl}, \mathrm{Co}, \mathrm{Cu}$, and $\mathrm{Zn}$ ), L-line (Ba, Sn, $\mathrm{Sr}$, and $\mathrm{Sb})$, and $\mathrm{M}$-line $(\mathrm{Pb})$ radiation using either $\mathrm{LiF}$ or PET diffracting crystals. A combination of wellcharacterized minerals and synthetic materials were used to calibrate for EPMA, including SMS scapolite (S and $\mathrm{Cl}$ ), Corning W glass [6] (Co), SMS gahnite (Zn), SMS cassiterite ( $\mathrm{Sn}$ ), SMS strontianite and Corning $\mathrm{X}$ glass ( $\mathrm{Sr}$ ). In the absence of a suitable primary standard, some elements were "self calibrated" using the Corning archeological glasses themselves, for example, Glass B $(\mathrm{Cu})$, Glass A ( $\mathrm{Sb})$, and Glass $\mathrm{C}(\mathrm{Ba}$ and $\mathrm{Pb})$. Corrections were made for the following first order peak interferences: $\mathrm{CuK}_{\beta}$ on $\mathrm{ZnK}_{\alpha}, \mathrm{SiK}_{\beta}$ on $\mathrm{SrL}_{\alpha}, \mathrm{KK}_{\beta}$ on $\mathrm{SbL}_{\alpha}$, and raw data were reduced using a ZAF matrix correction routine [7].

In order to establish the appropriate electron beam conditions to conduct the analyses, a series of measurements were made to determine the time dependence of $\mathrm{Na}, \mathrm{K}$, and $\mathrm{SiK}_{\alpha} \mathrm{X}$-ray intensities at a variety of current densities. Using a beam current of $20 \mathrm{nA}$ and a beam diameter of $10 \mu \mathrm{m}$, both the $\mathrm{Na}$ and $\mathrm{K}$ intensities dropped in Glass A as a function of time while the $\mathrm{Si}$ intensities rose in a complementary manner. This behavior suggests that heating resulting from energy lost by the electron beam caused interdiffusion of alkalis and silicon about the interaction volume. Conversely, a $30 \mathrm{nA}$ beam spread over a $30 \mu \mathrm{m}$ diameter produced stable intensities for all measured $x$ rays. Because each measurement for minor and trace elements was moderately long (120 s on peak and $60 \mathrm{~s}$ off peak position) beam conditions of $30 \mathrm{nA}$ and $40 \mu \mathrm{m}$ were chosen for all analyses.

On the basis of EPMA data alone the Corning glasses appear to be heterogeneous with respect to a number of metals (Table 2). Plots of the relative standard deviation of measurements (n typically 100) indicate that $\mathrm{SrO}$ and $\mathrm{ZnO}$ appear to be the most poorly homogenized across all compositions (Fig. 1a-d: upper plots). $\mathrm{BaO}$ and $\mathrm{SnO}_{2}$ are particularly heterogeneous in glass $\mathrm{B}$, and less so in

Table 2. Minor (and trace) element compositions of glasses by EPMA in mass fraction $\times 10^{2}$

\begin{tabular}{|c|c|c|c|c|c|c|c|c|c|c|c|c|c|c|c|c|}
\hline & $n$ & $\begin{array}{l}\text { A } \\
\text { Avg }\end{array}$ & $\operatorname{Sd}(1 \sigma)$ & Rel sd (\%) & $n$ & $\begin{array}{c}\text { B } \\
\text { Avg }\end{array}$ & $\mathrm{Sd}(1 \sigma)$ & Rel sd (\%) & $n$ & $\begin{array}{c}\text { C } \\
\text { Avg }\end{array}$ & $\operatorname{Sd}(1 \sigma)$ & Rel sd (\%) & $n$ & $\begin{array}{l}\text { D } \\
\text { Avg }\end{array}$ & $\operatorname{Sd}(1 \sigma)$ & Rel sd (\%) \\
\hline $\mathrm{BaO}$ & 105 & 0.47 & 0.05 & 10.1 & 102 & 0.09 & 0.04 & 46.7 & & & & & 152 & 0.30 & 0.04 & 15.0 \\
\hline $\mathrm{SnO}_{2}$ & 105 & 0.23 & 0.02 & 8.8 & 102 & 0.03 & 0.01 & 38.8 & 101 & 0.20 & 0.02 & 10.0 & 152 & 0.05 & 0.01 & 24.1 \\
\hline $\mathrm{SO}_{3}$ & 75 & 0.13 & 0.01 & 5.5 & 40 & 0.45 & 0.02 & 3.4 & 50 & 0.17 & 0.01 & 6.7 & 40 & 0.19 & 0.02 & 8.1 \\
\hline $\mathrm{Cl}$ & 105 & 0.09 & 0.01 & 14.5 & 102 & 0.16 & 0.02 & 15.3 & 101 & 0.07 & 0.01 & 10.6 & 152 & 20.16 & 0.02 & 11.9 \\
\hline $\mathrm{CoO}$ & 105 & 0.17 & 0.01 & 4.2 & 102 & 0.04 & 0.01 & 16.3 & 101 & 0.18 & 0.01 & 4.6 & 152 & 0.02 & 0.01 & 35.5 \\
\hline $\mathrm{CuO}$ & 105 & 1.20 & 0.05 & 3.8 & & & & & 101 & 1.17 & 0.05 & 4.3 & 152 & 0.36 & 0.03 & 8.8 \\
\hline $\mathrm{SrO}$ & 75 & 0.14 & 0.04 & 28.3 & 72 & bd & & & 71 & 0.27 & 0.06 & 20.5 & 80 & 0.06 & 0.03 & 54.1 \\
\hline $\mathrm{Sb}_{2} \mathrm{O}_{5}$ & & & & & 72 & 0.46 & 0.01 & 3.1 & 71 & bd & & & 80 & 0.84 & 0.02 & 3.0 \\
\hline $\mathrm{ZnO}$ & 10 & 0.05 & 0.01 & 24.7 & 10 & 0.19 & 0.01 & 6.0 & 10 & 0.05 & 0.02 & 30.3 & 80 & 0.14 & 0.04 & 30.8 \\
\hline $\mathrm{PbO}$ & 75 & 0.10 & 0.02 & 20.3 & 40 & 0.50 & 0.02 & 3.6 & & & & & 40 & 0.25 & 0.03 & 11.7 \\
\hline
\end{tabular}



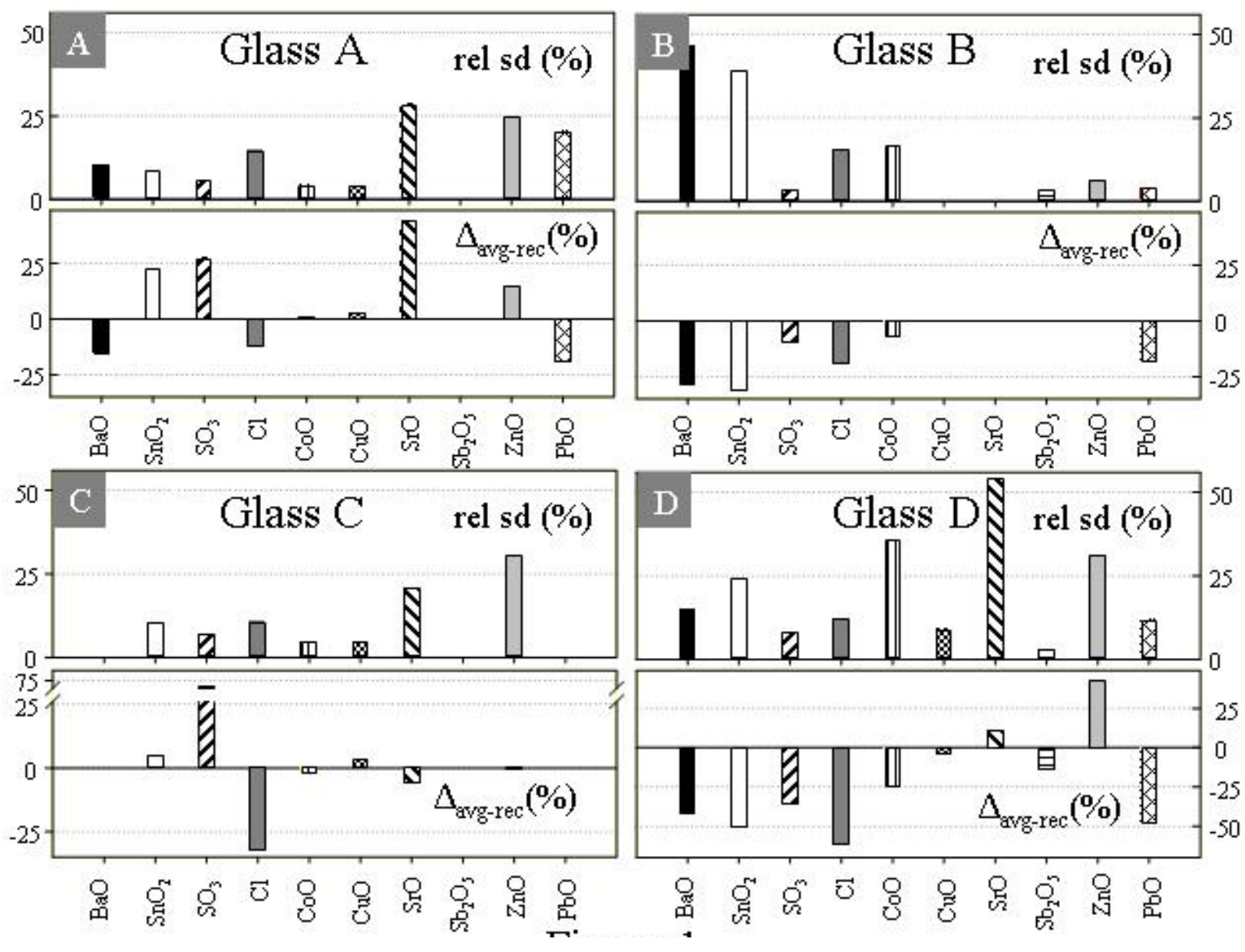

Fig. 1. Upper plots represent the homogeneity of glasses A, B, C, and D expressed as $1 \sigma$ relative (\%) of EPMA analyses. Lower plots show the relative difference between the recommended bulk and EPMA values. Measurement times of $120 \mathrm{~s}$ on peak/60 s off peak were used with a $40 \mu \mathrm{m}$ electron beam composed of $30 \mathrm{nA}$ of current.

glasses D and A. Conversely, the concentrations of $\mathrm{Sb}_{2} \mathrm{O}_{5}, \mathrm{CuO}$, and $\mathrm{SO}_{3}$ cluster more tightly in all glasses. Figure 1(a-d: lower plots) also shows that the agreement of the EPMA data with published bulk values is highly variable. In general, the $\mathrm{x}$-ray microanalysis values are typically lower than the published recommended concentrations for most metal oxides. Particularly poor agreement for $\mathrm{SO}_{3}$ concentrations may be attributed to the fact that both the $\mathrm{Cl}$ and $\mathrm{SO}_{3}$ are not known to a high degree of certainty, and were originally estimated by assuming incomplete retention of the their precursor chloride and sulfate during synthesis [4].

\section{Laser Ablation Inductively Coupled-Mass Spectrometry (LA ICP-MS)}

The ArF (193 nm) EXCIMER laser sampling system and ICP-MS instrumentation employed for analysis have been described in detail elsewhere [8,9]. A broad
$(25 \mathrm{~mm} \times 8 \mathrm{~mm})$ UV laser beam is used to illuminate an aperture, the image of which is demagnified 20 times onto the sample surface using a $150 \mathrm{~mm}$ focal length, UV-grade-silica doublet lens. Application of a laser fluence of $15 \mathrm{~J} / \mathrm{cm}^{2}$ results in uniform ablation and removal of $\approx 100 \mathrm{~nm}$ from the target material per laser pulse. Ablation is conducted in a $\mathrm{He}$ atmosphere in order to minimize sample recondensation during ablation about the target site and thereby maximize sample transport to the ICP [9]. The He flow $\left(300 \mathrm{~cm}^{3} / \mathrm{min}\right)$ containing the ablation products was subsequently combined with the main Ar carrier flow $\left(\approx 1000 \mathrm{~cm}^{3} / \mathrm{min}\right)$ prior to delivery via a signal smoothing device that damps the intrinsic laser pulsations in the signal, into the ICP.

The ICPMS instrument was operated in two modes of analysis. The first was optimized for maximum sensitivity on ${ }^{43} \mathrm{Ca},{ }^{88} \mathrm{Sr}$, and ${ }^{238} \mathrm{U}$ by rastering (scanning) a $65 \mu \mathrm{m}$ circular spot at a laser pulse repetition rate of 5 pulses/s across the NIST SRM 612 glass [10] while 
maintaining $\mathrm{ThO}^{+} / \mathrm{Th}^{+}$ratios $<0.5 \%$. This mode is designed to measure very low concentrations of trace elements and impurities. For these "impurity" measurements on the Corning glasses, a $65 \mu \mathrm{m}$ stationary spot was used and ions were collected for $60 \mathrm{~s}$. Sensitivities for analyte elements vary subject to the ionization efficiency, isotope abundance and position in the mass spectrum (with sensitivity generally increasing with mass). Eleven trace and minor elements $\left({ }^{7} \mathrm{Li},{ }^{11} \mathrm{~B},{ }^{51} \mathrm{~V}\right.$, $\left.{ }^{53} \mathrm{Cr},{ }^{60} \mathrm{Ni},{ }^{85} \mathrm{Rb},{ }^{88} \mathrm{Sr},{ }^{90} \mathrm{Zr},{ }^{138} \mathrm{Ba},{ }^{204} \mathrm{~Pb},{ }^{209} \mathrm{Bi}\right)$ and 16 impurities were measured in this mode of operation $\left({ }^{9} \mathrm{Be},{ }^{45} \mathrm{Sc},{ }^{71} \mathrm{Ga},{ }^{89} \mathrm{Y},{ }^{93} \mathrm{Nb},{ }^{95} \mathrm{Mo},{ }^{133} \mathrm{Cs},{ }^{140} \mathrm{Ce},{ }^{151} \mathrm{Eu}\right.$, ${ }^{175} \mathrm{Lu},{ }^{178} \mathrm{Hf},{ }^{181} \mathrm{Ta},{ }^{195} \mathrm{Pt},{ }^{205} \mathrm{Tl},{ }^{232} \mathrm{Th}$, and $\left.{ }^{238} \mathrm{U}\right)$. The second mode of operation involves rastering the sample with respect to the laser spot using a motorized stage driven at $1 \mathrm{~mm} / \mathrm{min}$. In this instrument setup, ablated material is sampled continuously across the entire transect length of a polished glass shard (e.g., $3 \mathrm{~mm}$ to $4 \mathrm{~mm}$ ). For the raster analyses in this study, a $23 \mu \mathrm{m}$ diameter laser ablation spot and $20 \mathrm{~Hz}$ laser pulse rate was employed. Twelve minor and trace elements were measured $\left({ }^{31} \mathrm{P},{ }^{47} \mathrm{Ti},{ }^{55} \mathrm{Mn},{ }^{57} \mathrm{Fe},{ }^{65} \mathrm{Cu},{ }^{68} \mathrm{Zn},{ }^{88} \mathrm{Sr},{ }^{118} \mathrm{Sn}\right.$, ${ }^{121} \mathrm{Sb},{ }^{137} \mathrm{Ba}$, and ${ }^{208} \mathrm{~Pb}$ ). Major elements were also collected but are not reported here. Most analyte isotope sensitivities range between $\approx 150$ and 1000 counts $\times \mathrm{s}^{-1}$ $\times$ mass fraction $\times 10^{6}$ in the laser rastering setup and between 5000 and 20000 counts $\times \mathrm{s}^{-1} \times$ mass fraction $\times 10^{6}$ in the point analyses.

All standards and unknowns were analysed using a point analysis procedure. ${ }^{43} \mathrm{Ca}$ was employed as the internal standard based on recommended bulk $\mathrm{CaO}$ concentrations [11]. A drift correction was applied to the unknowns between the bracketing NIST SRM 612 calibrations, assuming a linear variation in measured signal intensity ratios with the analysis sequence. The analysis protocol involved external calibration of the instrument using the NIST SRM 610 glass (raster analyses) and NIST SRM 612 (point analyses) and subtraction of "gas" (laser off) background count rates from all measured signal intensities. All reference materials and background measurements were measured for a period of $90 \mathrm{~s}$, operating the ICP-MS in simultaneous pulse counting/peak hopping mode, and acquiring data on a single point per isotope using $20 \mathrm{~ms}$ dwell times for most internal standard and analyte isotopes.

The results of the raster analysis for glasses $\mathrm{A}, \mathrm{B}$, and D are shown in Figs. 2, 3, and 4, respectively. Because

Oxide (mass fraction $\mathrm{x} 10^{2}$ )

Glass A

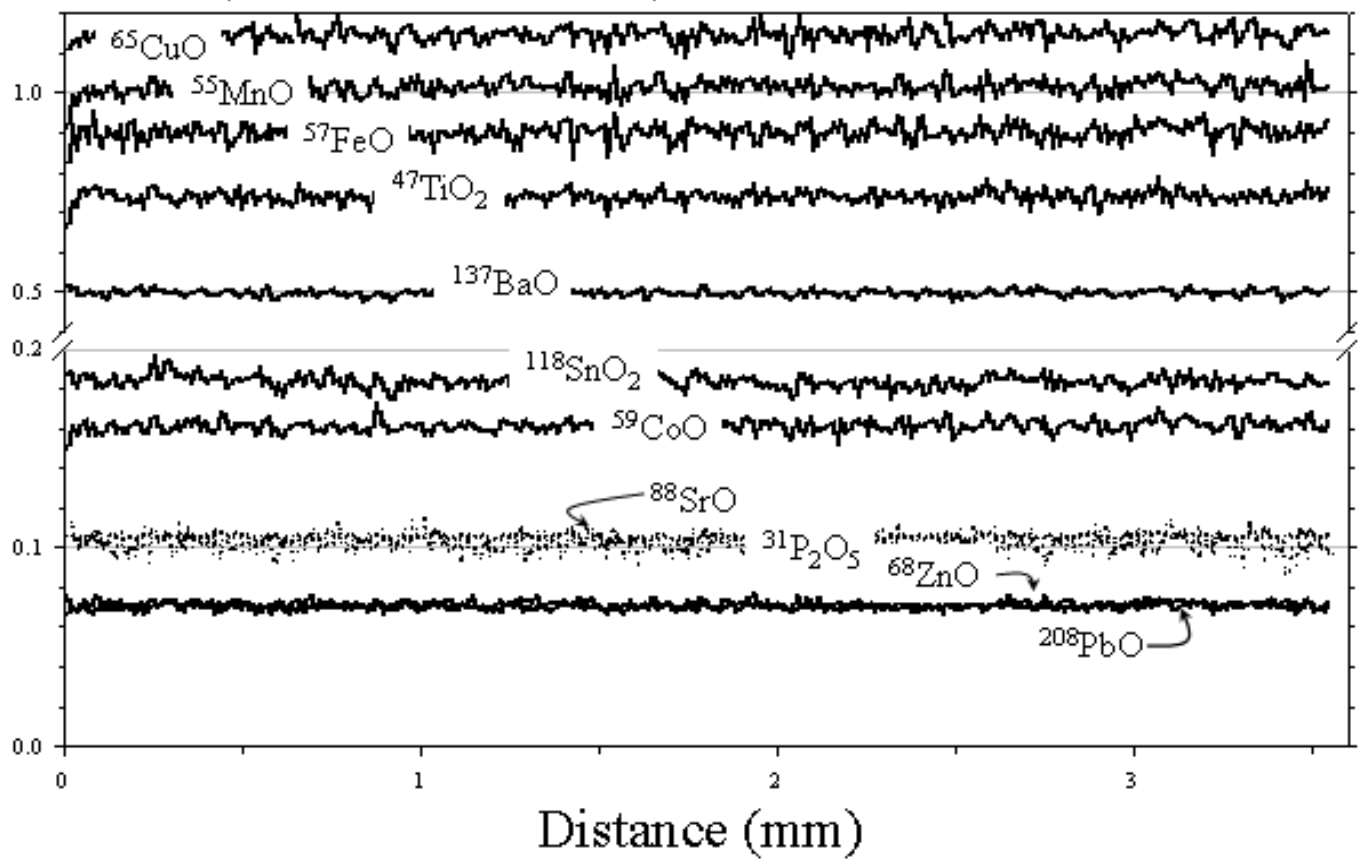

Fig. 2. LA ICP-MS minor and trace element profiles by raster mode, or continuous grid sampling of glass A. The sample was translated at $1 \mathrm{~mm} / \mathrm{min}$ under a $23 \mu \mathrm{m}$ laser spot operated at $20 \mathrm{~Hz}$ laser pulse rate. 


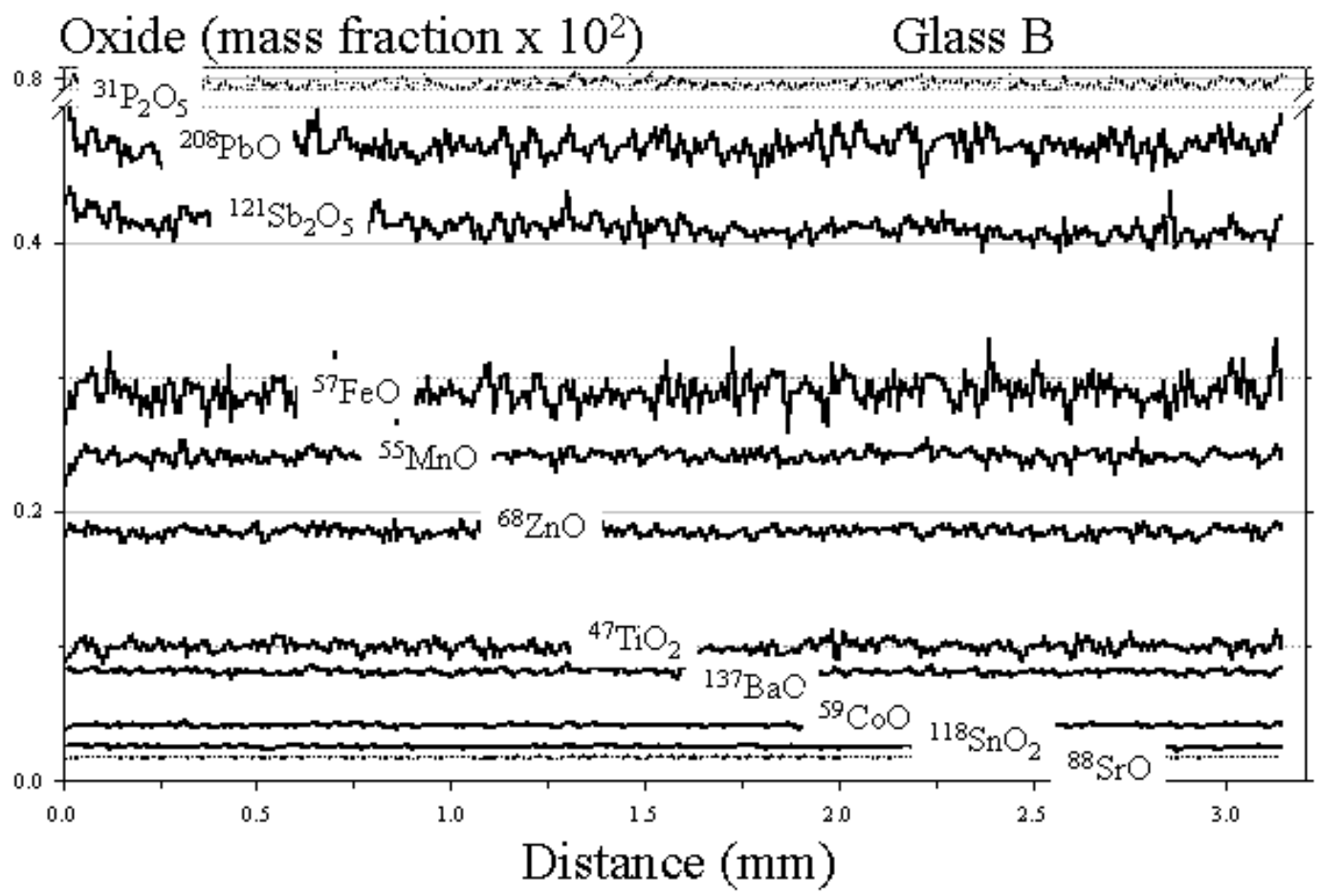

Fig. 3. LA ICP-MS minor and trace element profiles by raster mode, or continuous grid sampling of glass $B$. The sample was translated at $1 \mathrm{~mm} / \mathrm{min}$ under a $23 \mu \mathrm{m}$ laser spot operated at $20 \mathrm{~Hz}$ laser pulse rate.

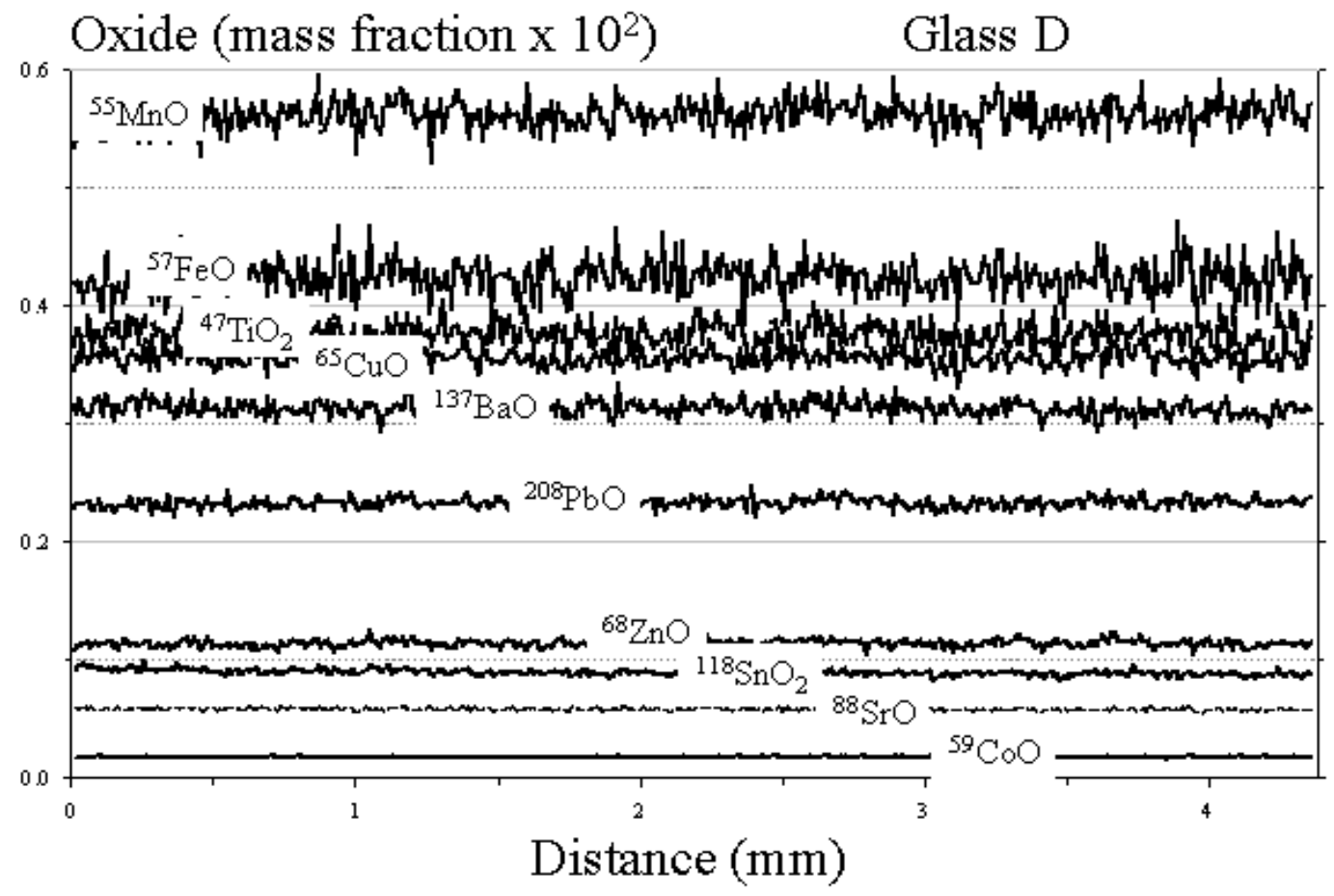

Fig. 4. LA ICP-MS minor and trace element profiles by raster mode, or continuous grid sampling of glass D. The sample was translated at $1 \mathrm{~mm} / \mathrm{min}$ under a $23 \mu \mathrm{m}$ laser spot operated at $20 \mathrm{~Hz}$ laser pulse rate. 
this method of sampling is virtually continuous and covered many millimeters of the polished surface, these data represent the best estimate for determining microchemical heterogeneity in the glasses. The profiles of all oxides show remarkable degree of homogeneity for minor and trace components. Relative standard deviations of analyses are typically less than $2 \%(1 \sigma)$ and often less than $1 \%$. Agreement between the raster LA ICP-MS values and published bulk values is highly variable but typically within $5 \%$ to $20 \%$.
Only three spot mode analyses were collected from each glass so information regarding heterogeneity is strictly limited. In broad terms, the trace elements measured in this style of operation showed better agreement with the recommended or theoretical published values for the bulk glasses than were minor elements (Fig. 5). Nearly all impurities are present at the level of less than $10^{-6}$ mass fraction. (Table 3 ). Pt which was used in the synthesis process is found in single mass fraction $\times 10^{6}$ abundances, though it can be traced to the stirring elements used during glass synthesis.

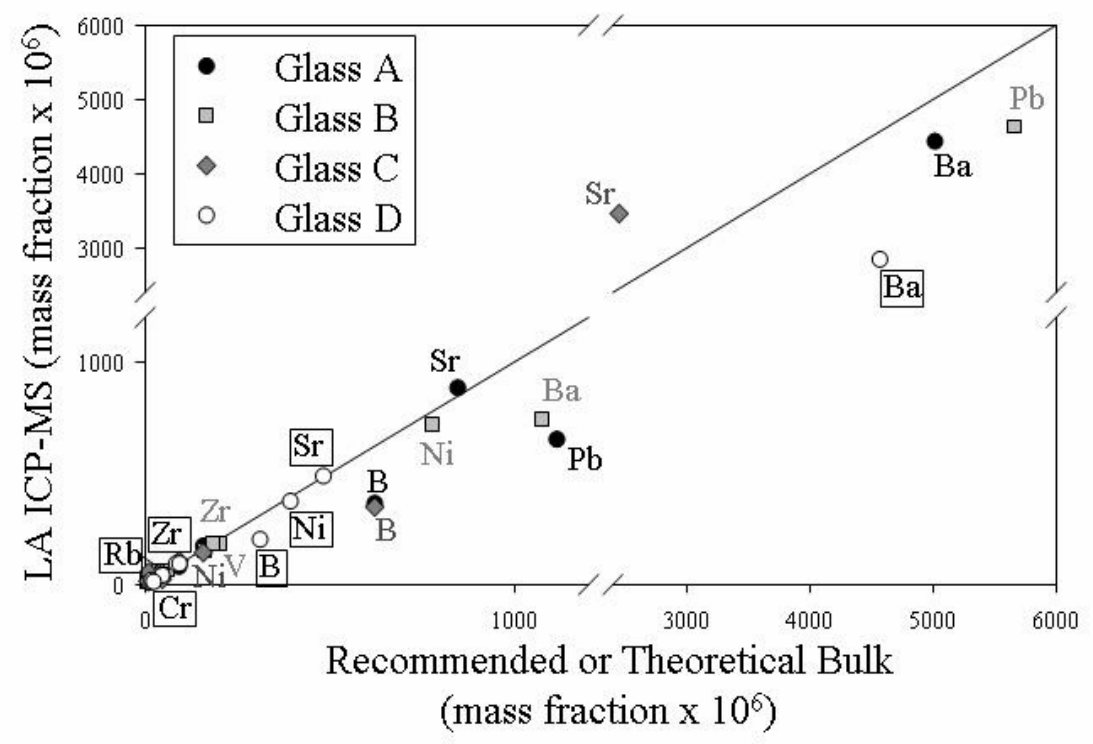

Fig. 5. LA ICP-MS results versus either the recommended, or theoretical bulk values for minor and trace elements obtained by spot mode analysis. A $65 \mu \mathrm{m}$ stationary laser spot was used to collect ions for $60 \mathrm{~s} / \mathrm{measurement}$.

Table 3. Impurities in glass by spot mode LA ICP-MS in mass fraction $\times 10^{6}$

\begin{tabular}{|c|c|c|c|c|c|c|c|c|}
\hline \multirow{3}{*}{$\begin{array}{c}\text { Glass } \\
n\end{array}$} & A & \multicolumn{3}{|c|}{ B } & \multirow{2}{*}{\multicolumn{2}{|c|}{$\begin{array}{l}\mathrm{C} \\
3\end{array}$}} & \multicolumn{2}{|l|}{ D } \\
\hline & 3 & & 3 & & & & 3 & \\
\hline & Avg & $\mathrm{Sd}$ & Avg & $\mathrm{Sd}$ & Avg & $\mathrm{Sd}$ & Avg & $\mathrm{Sd}$ \\
\hline${ }^{9} \mathrm{Be}$ & 0.06 & 0.01 & 0.07 & 0.003 & 0.02 & 0.005 & 0.03 & 0.02 \\
\hline${ }^{45} \mathrm{Sc}$ & 0.566 & 0.009 & 0.549 & 0.020 & 0.311 & 0.028 & 0.496 & 0.004 \\
\hline${ }^{71} \mathrm{Ga}$ & 0.595 & 0.010 & 2.43 & 0.02 & 0.405 & 0.003 & 2.38 & 0.04 \\
\hline${ }^{89} \mathrm{Y}$ & 0.365 & 0.008 & 0.474 & 0.007 & 4.284 & 0.084 & 0.370 & 0.002 \\
\hline${ }^{93} \mathrm{Nb}$ & 0.598 & 0.003 & 0.179 & 0.003 & 0.744 & 0.004 & 0.559 & 0.008 \\
\hline${ }^{95} \mathrm{Mo}$ & 3.23 & 0.01 & 1.66 & 0.03 & 3.30 & 0.40 & 3.32 & 0.11 \\
\hline${ }^{133} \mathrm{Cs}$ & 0.255 & 0.005 & 0.061 & 0.002 & 0.368 & 0.017 & 0.140 & 0.001 \\
\hline${ }^{140} \mathrm{Ce}$ & 0.236 & 0.002 & 0.164 & 0.003 & 0.046 & 0.001 & 0.256 & 0.002 \\
\hline${ }^{151} \mathrm{Eu}$ & 0.012 & 0.001 & 0.004 & 0.001 & 0.126 & 0.004 & 0.007 & 0.001 \\
\hline${ }^{175} \mathrm{Lu}$ & 0.005 & 0.001 & 0.019 & 0.001 & 0.024 & 0.001 & 0.011 & 0.001 \\
\hline${ }^{178} \mathrm{Hf}$ & 0.949 & 0.007 & 4.152 & 0.018 & 1.677 & 0.011 & 2.115 & 0.033 \\
\hline${ }^{181} \mathrm{Ta}$ & 0.124 & 0.003 & 0.089 & 0.003 & 0.120 & 0.002 & 0.231 & 0.004 \\
\hline${ }^{195} \mathrm{Pt}$ & 4.21 & 0.68 & 1.33 & 0.01 & 8.56 & 2.89 & 0.80 & 0.0 \\
\hline${ }^{205} \mathrm{Tl}$ & 0.06 & 0.01 & 0.20 & 0.01 & 18.53 & 0.49 & 0.10 & 0.00 \\
\hline${ }^{232} \mathrm{Th}$ & 0.288 & 0.001 & 0.805 & 0.013 & 0.204 & 0.003 & 0.648 & 0.005 \\
\hline${ }^{238} \mathrm{U}$ & 0.1823 & 0.0025 & 0.2258 & 0.0046 & 0.0786 & 0.0013 & 0.1603 & 0.0014 \\
\hline
\end{tabular}




\section{Secondary Ion Mass Spectrometry (SIMS)}

A magnetic sector secondary ion mass spectrometer using a $25 \mu \mathrm{m}$ diameter $\mathrm{Cs}^{+}$primary ion beam was used to measure ${ }^{32} \mathrm{~S}$ and ${ }^{35} \mathrm{Cl}$, as well as impurity levels of ${ }^{1} \mathrm{H},{ }^{12} \mathrm{C}$, and ${ }^{19} \mathrm{~F}$. Secondary ions were extracted in the negative polarity, measured at a mass resolution of $\approx 2400 \mathrm{~m} / \Delta \mathrm{m}$ (full width at half maximum), and detected with an electron multiplier. The instrument was calibrated using volcanic glasses standards and procedures described by Hauri et al. [12].

Six analyses per glass were collected. The relationship between the SIMS results and nominal bulk concentrations of $\mathrm{S}$ and $\mathrm{Cl}$ are shown in Fig. 6. As discussed above, the lack of a better correlation likely stems from uncertainty in the degree of volatile loss during glass synthesis. Volatile impurities are listed in Table 4. A small but measurable amount of hydrogen is present in all glasses. Despite high temperature processing $\mathrm{H}$ (expressed as $\mathrm{H}_{2} \mathrm{O}$ ) was stable in the silicate melts at the $10^{-4}$ mass fraction level at room pressure. A double polished thin section of each glass was made, and transmission Fourier transform infrared spectra were collected that confirmed the presence of hydroxyl in the glasses.

\section{Summary}

While EPMA offers the highest spatial resolution of the three methods employed, the measurement times become impractically long when attempting to measure large groups of elements present at the 0.0001 mass fraction to 0.001 mass fraction level. This fact may account for the discrepancy between the fairly large degree of chemical heterogeneity in the glasses suggested by EPMA, relative to the high degree of compositional uniformity indicated by raster mode LA ICP-MS. Because LA ICP-MS is a high precision method, coupled with the significantly larger volume of material sampled in the raster mode, we can state with certainty that these glasses show promise for use as secondary standards of minor and trace elements. Because these materials are now part of the

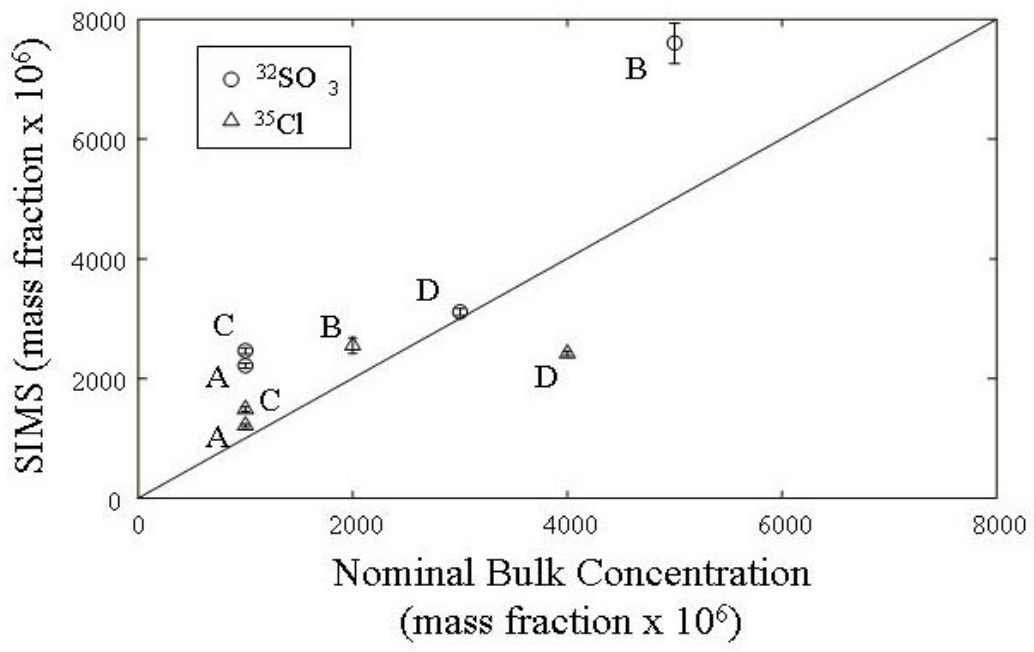

Fig. 6. SIMS results versus the nominal bulk values for $\mathrm{SO}_{3}$ and $\mathrm{Cl}$. A $25 \mu \mathrm{m} \mathrm{Cs}{ }^{+}$primary ion beam was used to sputter the sample surface. Negative secondary ions were collected using a moderate mass resolution and an electron multiplier ion detector.

Table 4. Impurities in glass by SIMS in mass fraction $\times 10^{6}$

\begin{tabular}{rrrrr}
\hline \hline Glass & A & B & C & D \\
\hline${ }^{1} \mathrm{H}_{2} \mathrm{O}$ & 180 & 320 & 310 & 290 \\
$1 \sigma$ & 20 & 20 & 20 & 20 \\
${ }^{12} \mathrm{CO}_{2}$ & bd & bd & bd & bd \\
${ }^{19} \mathrm{~F}$ & 34.0 & 69.6 & 33.1 & 45.9 \\
$1 \sigma$ & 0.5 & 2.5 & 0.5 & 0.9 \\
\hline
\end{tabular}


Smithsonian Microbeam Standard collection, it is hoped that research laboratories will request material to perform follow-up microbeam characterization of the archeological reference glasses.

\section{Acknowledgments}

We thank Dr. Robert H. Brille of the Corning Museum of Glass for donating material for this study. $\mathrm{He}$ is also responsible for the transfer of the glasses to the Smithsonian Institution for distribution to laboratories worldwide. Eugene Jarosewich (chemist emeritus) performed some initial analyses at the Smithsonian Institution which inspired the present study. We would also like to thank Mr. Timothy Gooding (National Museum of Natural History) for preparing samples, and Dr. Erik Hauri of the Carnegie Institution of Washington for providing expertise in secondary ion mass spectrometry. Finally, we acknowledge the Joseph White Sprague Endowment for financial support the Analytical Laboratories in the Department of Mineral Sciences.

\section{References}

[1] W. E. S. Turner, in Advances in Glass Technology, Plenum Press, New York, Vol. Part No. 2 (1963) pp. 384-387.

[2] R. H. Brill, in VIIth International Congress on Glass, Brussels, Belgium (1965).

[3] R. H. Brill, in VIIIth International Congress on Glass, Sheffield, England (1998) pp. 47-68.

[4] R. H. Brill, in IXth International Congress on Glass, Versailles, France (1971) pp. 93-110.

[5] E. Jarosewich, J. Res. Natl. Inst. Stand. Technol. 107, 681-685 (2002).

[6] P. Carpenter, J. Res. Natl. Inst. Stand. Technol. 107, 703-718 (2002).

[7] J. T. Armstrong, Microbeam Anal. 4, 177-200 (1995).

[8] S. M. Eggins, L. P. J. Kinsley, and J. M. G. Shelley, Appl. Surface Sci. 127-129, 278-286 (1998).

[9] S. Eggins, R. L. Rudnick, and W. F. McDonough, Earth Planetary Sci. Lett. 154, 53-71 (1998).

[10] S. Eggins and J. M. G. Shelley, Geostand. Newslett. 26 (2002).

[11] R. H. Brill, in Chemical Analyses of Early Glasses, Canfield and Tack, Rochester, New York (1999) pp. 527-544.

[12] E. Hauri, J. Wang, J. E. Dixon, P. L. King, C. Mandeville, and S. Newman, Chem. Geol. 183, 99-114 (2002).

\begin{abstract}
About the authors: Dr. Edward Vicenzi is a research geochemist at the Smithsonian Institution's National Museum of Natural History. He has served as the director of the Analytical Laboratories in the Department of Mineral Sciences since 1999. Previously he was a research staff member in the Princeton Materials Institute at Princeton University for 6 years. Dr. Vicenzi was a research fellow at Macquarie University, Australia for 2 years after receiving his PhD from Rensselaer Polytechnic Institute. His primary focus is studying Earth and planetary processes by measuring and imaging microscale chemical variability in geological materials. Dr. Stephen Eggins is a research fellow in the Petrochemistry and Experimental Petrology group at Australia National Universitys Research School of Earth Sciences. He has been active in developing the LA ICP-MS technique for the study of volcanic glasses and minerals. Dr. Amelia Logan is a chemist in the Department of Mineral Sciences at the Smithsonian Institution, and research assistant professor at the George Washington University. Dr. Richard Wysoczanski is a postdoctoral fellow currently studying the volatile contents of volcanic glasses, also in the Department of Mineral Sciences at the Smithsonian Institution.
\end{abstract}

